\title{
Alan Antropolojisinin Sorunları ve Yöntemleri: Çerkes Diasporası
}

\author{
Madina Pashtova* \\ Çev. Murat Topçu (Papşu)
}

\begin{abstract}
Özet
Çerkes nüfusunun \% 90'ını oluşturan ve dünyanın 50'den fazla ülkesine dağılmış diasporası, Rus-Kafkas Savaşı'na (19. Yüzyıl) ve iki dünya savaşına bağlı olarak oluştu. Makale yazarının gözlemleri Türkiye'nin yerel Çerkes kültürel adacıklarından biri olan Uzunyayla'da 2009, 2011, 2014 ve 2015 yıllarında gerçekleştirilen alan araştırmaları sırasında yapıldı. Alan çalışmasında kişiler arası ve gruplar arası iletişimin etnik özellikleri incelendi. Bu makalede Çerkes diasporasında otantik folklorun (dilin ve geleneksel kültürün) taşıyıcılarının azalması, derlemecinin ve kaynak kişilerin sosyal (toplumsal davranış, etik, toplumsal cinsiyet) iletişimi gibi halkbiliminin ve antropolojinin sorunları ele alınıyor.
\end{abstract}

Anahtar Sözcükler: Çerkes, folklor/halkbilim, alan antropolojisi, Türkiye, diaspora, derlemeci.

* Filoloji bilimleri adayı, Adıgey Cumhuriyeti Beşeri Araştırmalar Enstitüsü, Maykop, Rusya Federasyonu.gupsa@mail.ru

Makale, Rusça olarak 19-30 Ekim 2015 tarihinde Kabardey-Balkar Cumhuriyeti'nin başkenti Nalçik'te yapılan “XVI. Yüzyıl - XX. Yüzyıl Başı Arasında Merkezi ve Kuzeybatı Kafkasya'nın Sosyo-Politik ve Kültürel Alanı: Entegrasyon Süreçlerinin Yönelimleri ve Dinamiği" konulu konferansın sunum metni olarak yayımlanmıştır. (Nalçik, 2015).

Паштова М.М. «Проблемы и методы полевой фольклористики: диаспорное поле» // Сборник научных статей по материалам региональной научно-практической интернет-конференции «Социально -политическое и культурное пространство Центрального и Северо-Западного Кавказа в XVI - начале XX в: направления и динамика интеграционных процессов» (Нальчик, 19-30 октября 2015 г.). Нальчик, 2015. C. 198-207. http://www.kbigi.ru/fmedia/conf/Pashtova.pdf 


\title{
Problems and Methods of the Field Anthropology: The Circassian Diaspora
}

\begin{abstract}
The Circassian diaspora, which was formed as a result both of the Russian-Caucasian War in the mid 1860s and of the two world wars of the 20th century, reside in more than fifty countries around the world and comprise almost 90\% of the world's Circassian population. This article is based on the materials the author collected and the observations she made during field trips in 2009, 2011, 2014 and 2015 to one of the Circassian cultural enclaves in Turkey, the Uzunyayla region of the Central Anatolian city of Kayseri. In this field study, the ethnic aspect of interpersonal and intra-group communication is investigated. The article also deals with the decrease, over the years, in the numbers of informants who continue to carry the traditional culture and linguistic heritage, as well as the social aspects (i.e. etiquette, ethic, gender) of the communication between the researcher and the informant, which are the problems of the academic disciplines of folklore and anthropology.
\end{abstract}

Keywords: Circassians, Adyghes, folklore, anthropology, field folklore, Turkey, diaspora, legendary (collector), informant.

Önceki çalışmalarda belirttiğimiz gibi (Paştova 2012 ve 2014), yazı, kültür ve eğitimle ilgili devlet kurumlarının olmaması nedeniyle Çerkes diasporasında tarihi vatanıyla karşılaştırılamayacak kadar büyük "yüksek statülü" kaynak kişi sayısı gözlenir. Bu tespitle kaynak kişilerin sosyal, en başta da dil ve etnik bilgi yeterliliği, bildirdiği metnin otantikliği kastedilir.

Diasporanın iletişim alanında biçimsel olmayan, geleneksele yakın spesifik özellikler hakimdir. Bu koşullarda "folklor sözü"” sosyal

\footnotetext{
1 Rusya'da beşeri bilimlerde folklor kavramının, son zamanlarda antropolojik anlamı genişlemiş olsa da, sözel (verbal) önceliği hala korunmaktadır. "Folklor sözü" ile folklorun taşıyıcıları olan yaşlıların söylediklerini, yani edebiyat ve bilim dışı olan, yayınlanmamış sözlü halk kültürünü kastediyorum.
} 
düzenlemenin, etno-kültürel ve sosyal doyumun, etnik özgünlük ve yaşam sorunlarının çözümünün en etkili araçlarından biri olarak karşımıza çıkar. Yüksek düzeyde korunmuş ve itibarlı olması da bununla açıklanır. Dolayısıyla, sözlü kültür metinlerinin teknik taşıyıcılar (kim tarafından yapılırsa yapılsın - yerel amatörler veya dışarıdan gelen profesyoneller) yardımıyla kayda geçirilmesi çabası kaynak kişiler tarafından "son derece yararlı ve asil bir iş" olarak görülür.

$\mathrm{Bu}$ makalede kaynak kişi ile derlemeci arasındaki iliş̧inin diaspora alanına özgü birkaç önemli yönü üzerinde durmak istiyoruz.

Bu araştırmanın materyali kalıp (stereotip) sözlü anlatılar, kaynak kişi ile derlemeci arasındaki dialoglar, alan çalışması sırasında kişiler arası ve gruplar arası iletişimin etnik özelliklerine dikkat çeken halkbilimci meslektaşlarımızın aktardıklarıdır. Gözlemlerim Türkiye'nin yerel kültür adacıklarından biri olan Uzunyayla'da 2009, 2011, 2014 ve 2015 yıllarındaki araştırma gezilerim sırasında yapıldı.

Araştırma Yöntemleri: Gözlem ve yapılandırılmamış mülakat, internet aracılığıyla anket; işitsel ve görsel kayıtlar, elle tutulan notlar.

Edinilen kayıtların hareketliliği, bilgiselliği ve kaydedilen metnin niteliksel özellikleri hem derlemecinin tercih ettiği hareket stratejisine, onun dilsel, kültürel, toplumsal davranış kodlarına bağlı sosyal ve profesyonel yetkinliğine, hem de bunu ilgili durum için uygun formlarda gerçekleştirebilme becerisine bağlıdır.

Kaynak kişinin tutumunun niteliği ise şunlara bağlı olabilir:

- Kaynak kişinin cinsiyetine, yaşına ve sosyal statüsüne ve bunlara da bağlı olan kültürel repertuvarına; ${ }^{2}$

- Derlemecinin "bizden" veya "yabancı" oluşuna;

\footnotetext{
${ }^{2}$ Özellikle yaşlı kaynak kişilerin her birinin kendi repertuvarı vardır. Kimi eski söylenceler anlatır ve kahramanlık şarkıları söyler, kimi de sadece anekdotlar anlatır. Kaynak kişinin repertuvar statüsü de bununla belirlenir. Diasporada kaynak kişinin folklor repertuvarı statüsü genellikle onun sosyal statüsüyle bağlantılıdır. Gençliğinde saygın haçeş toplantılarında çok zaman geçirmiş yaşlılar genellikle "klasik" folklor taşıyıcısı olurlar ve yüksek repertuvar statüleri vardır. Araştırmacılar özellikle onları arar ve kaydeder.
} 
- Kaynak kişinin "açık" (verici) veya "kapalı" (profan) oluşuna; ${ }^{3}$

- Mülakat konusuna;

- Derlemeciye eşlik eden üçüncü kişinin (oralı hağarey) sosyal statüsüne;

- Kayıt yerine (genel/kişisel mekan/yabancı mekan) ve onun yapılandırılışına.

Öncelikle derlemecinin Çerkes diasporasında aristokrat geleneklerinin canlı olduğunu unutmadan, kaynak kişinin sosyal "çözülme" durumunu dikkatle izlemesi gereklidir. Bazı durumlarda en iyi ihtimalle geçmişteki sosyal eşitsizliğin aşılması bağlamında insani yansımalar kaydedersiniz. Bununla birlikte, kayıt sırasında bunların gündeme gelmesi veya suskunlukla geçiştirilmesi birçok bakımdan derlemeciye bağı olacaktır: Yerel topluluğun sosyal yapısının özelliklerini bir gerçeklik olarak kabul ediyor musunuz? Sosyal ve hiyerarşik farklııkların kısa zaman öncesine kadar korunmasının nedenlerini kendinize nasıl açıklıyorsunuz? En önemlisi de kaynak kişinin bunu anlamasını nasıl sağlıyorsunuz?

Geleneğin taşıyıcıları folklor repertuvarını "itibar" ölçütüne göre rahatlıkla ayırırlar: haçeş hıbar (хьэщІэщ хъыбар) (seçkin erkek meclisleri olan konuk odalarında anlatılan hikayeler) ve mejgit gabe hıbar (мэжг'ым г'абэ хъыбар) (cami duvarı dibinde anlatılan hikayeler). Kaynak kişilerimizin görüşlerine de dayanarak, folklor repertuvarının bazı türlerinin "aristokrat" ve "erkek"ten farklı olarak köylü, çocuk ve kadın yaşantısına ait daha az itibarlı kategoriye dahil edildiğini söyleyebiliriz. Bu, anlatıcının aktardığıyla ilişkisine ve genel olarak bu konuda konuşmayı isteyip istememesine bağlıdır.

Araştırmamız sırasında kaynak kişinin sosyal "kapalıık" etkeninin sadece ilk kayıtta gerçekleştiği durumlar oldu. Fakat bir yıl sonra, ikinci kayıt sırasında en yaşlı ve itibarlı kaynak kişilerden bazıları mahrem sayarak verdikleri bilgiden bilinçli olarak "sosyal tabu"yu kaldırdılar.

Çerkes diasporasının folklorunda ve çağdaş sosyo-kültürel

3 Açık (verici) veya kapalı (profan) kültür semiotiğinde kullanılan terimlerdir. Açık (verici) bilgi sahibi, "kendi" olan, ne dendiğini hemen anlayan, uzun açıklamalar yapılması gerekmeyen kişidir. Kapalı (profan) ise verici olmayan, konuşulanı anlamayan, konu hakkında bilgisi olmayan kişidir. 
alanında erk ve aristokrasi söylemi, aynı şekilde bu konunun derlemecinin ve kaynak kişinin sohbetinde ortaya çıkma biçimleri ayrı bir araştırma konusudur.

Alan araştırmasının toplumsal cinsiyet yönünün birbiriyle bağlantılı birkaç vektörü (rol kombinasyonları ve çalışma perspektifleri) vardır:

1) Kadın derlemeci ve erkek kaynak kişi,

2) Erkek derlemeci ve kadın kaynak kişi,

3) Kadın derlemeci ve kadın kaynak kişi,

4) Erkek derlemeci ve erkek kaynak kişi.

$\mathrm{Bu}$ makalede araştırma gezimizin bütün ayrıntıları üzerinde durmayacağız, sadece iki detayı ele alacağız. Kadın derlemeciye yaşından, hangi ülkeden geldiğinden bağımsız olarak toplumsal davranış kuralları gereği yüksek ilgi gösterilir, maddi ve manevi destek sağlanır, ${ }^{4}$ ancak bununla birlikte kaynak kişinin "çözülmesi" geleneksel davranış biçimiyle ("екly-емыкly" - "uygun-uygunsuz") sınırlıdır ve derleyicinin yerel geleneğe "nüfuzunun" geçmişiyle belirlenir. Kadın kaynak kişi diaspora alanında, İslam kültürünün taşıyıcısı olarak, video kaydını istemeyebilir. Bizim araştırmamız sırasında böyle olaylarla son derece seyrek karşılaşıldı ve bu sadece kaynak kişilerin bilinçli seçiminden değil, geleneksel olarak Çerkes kadınının geniş özgürlüğünden de kaynaklandı.

Açık avantajlarının yanında video kamerayla çalışma derlemecinin karşısına, etnik (mental) kaynaklı bir dizi problem çıkarır. Çağdaş metodolojide kaynak kişinin tesadüfi, benmerkezci sapmalarına kadar her şeyi kaydetme eğilimi yaygındır. Burada, doğal olarak, kaydedilen metnin otantikliği kavramıyla ilintili bazı sorunlar ortaya çıkar. Kabul etmek gerekir ki, elinde kamerayla törensel mekanı işgal eden biri eylemin doğal gidişatını ve doğallığını bozar, gizli video çekimi ise araştırmacının kaynak kişi üzerindeki negatif

${ }^{4}$ Çerkeslerle yapılan araştırmanın özelliklerinden birisi, araştırmacıya en iyi Kafkas konukseverliği içinde, barınmadan ulaşıma kadar yabancı bir ülkede çalışmak için gerekli her şeyin sağlanmasıdır. Genellikle bu işlevi Çerkes dernekleri yerine getirir. Fırsattan istifade, 2014 ve 2015 yıllarındaki gezilerin organizasyonunda yardımları için Kayseri Kafkas Derneği yönetimine ve yönetici Mutlu Akkaya'ya (Mamheğ) teşekkür etmek isterim. 
etkisini azaltır. [Klyaus].

Gizli kayıt, derlenen tüm folklor metninin doğallığını (otantikliğini) korumaya yaramakla birlikte, bu, derlemeciye onun sonradan kullanımı konusunda büyük sorumluluk yükler.

Derlemeci iletişimin geleneksel tiplerine yakın durumlar modelleyebilmek, agonal (atışmalı) tipte geleneksel sohbetlere (vorşer) katılmak zorundadır. Yukarıda belirttiğimiz gibi, daha çok biçimsel olmayan, gayri resmi (yatay) iletişim kanallarının korunduğu Çerkes diaspora ortamında bu, başarılı bir alan çalışması yapmanın koşullarından biridir.

Alan çalışmamı sırasında birçok kayıt seansı, konuk odalarında haçeş zehes (хьэщ)эщ зэхэс), jeşdes (жэщдэс), vorşerako (уэршэракlуэ), şısako (щысакlуэ) gibi ritüel "oturma-sohbet" biçiminde düzenlendi. Profesyonel kişilerce yapılan ses- video kaydı süreci, benzer geleneksel iletişimsel durumları yeniden yaratabilir. Örneğin, R.B. Unarokova tarafından, araştırmacıların Türkiye'de özel evleri ve Çerkes derneklerini ziyaretleri sırasında gerçekleşen bazı iletişimsel durumlar ayrıntılı şekilde tasvir edildi. Çerkes dernekleri on yıllardır geleneksel konuk evi işlevini yerine getirmektedir. Stereotipik sözlü takılmalar (şakalar) konusunda da yazar, araştırma grubu üyelerinin birçok kez tanık, bazen de katılımcı olduklarına işaret ediyor [Unarokova: 17].

Kaynak kişi tarafından sezgisel olarak dialog biçiminde kurulan konuşmaya dahil edilen derlemecinin bazen kendini asıl konuşulan olarak konumlandırması gerekir. Bu, kaynak kişiye, muhtemel izleyiciler karşısında yetkinliğinin korunduğu hissini verir. Üçüncü kişilerin varlığı, yani çoklu konuşma durumunda iletişim sık sık karakteristik agonistik (rekabetçi) özellikler kazanır, ki bu Çerkeslerin mental verili davranış tarzı olarak ortaya çıkar. Bununla birlikte, bizzat derlemecinin yerel gelenekteki statüsünün önemi vardır: "bizden veya yabancı", "yabancı" ise (o zaman) "konuk". Sosyal ve/veya profesyonel yetkinliği, iradesini ortaya koyma becerisi ve rol vurgularını "doğru" yapması, önsel (a priori) kurulan ilişkilerden (sosyal, ailevi, yaş-cinsiyet vd.) bağımsız olarak konuşmayı yönlendirmesi önemlidir. En önemli koşul ise psikolojik konforu, iletişimin resmi olmayan, "röportaj dışı" atmosferini sağlayabilmektir. 
Heku (Anavatan) temsilcisi olarak derlemeci ile sürgün sonucunda yüz elli yılda oluşan bir topluluğun temsilcisi olarak kaynak kişi arasındaki dialoğun motifleri ve nedenleri halen örtük olarak "açıklanır"; "uzun ama şansız bir yaşam" / "kahramanca ölüm" karşıtlığında yatan geleneksel ideolojik motiflerle de modellenirler. "Ölüm" bu bağlamda semantik olarak ata topraklarının kaybıyla ve yabancı ülkede "hehes" (хэхэс- $\left.x^{\prime} э у x^{\prime} э c\right)-$ "dışarlıkıı" statüsü almış olmakla ilişkilendirilir.

Özellikle son on yıllarda oluşan "Türk devletinin kuruluşuna aktif olarak katılan Çerkeslerin hizmetleri", "Çerkeslerin yaşadıkları ülkelerin siyasi yaşamına aktif katılımları" biçimindeki söylem, her şeyden önce "hehes" statüsünün aşılmasına yöneliktir. Diasporanın sosyoloji bilimi alanında bu konuya çok ilgi gösterilir. Bu söylem en uç biçimlerini şu tür kalıp ifadelerde alır: "Çerkesler diaspora halkıdır, kültürümüzü başka ülkelerde de korumak zorundayız", "Türkiye bizim ikinci vatanımı" vb.

Bu dil pratikleri "dönüşçülük" karşıtı söylem olarak görülebilir. Kafkasya'daki yaşam hakkındaki olumsuz kalıp yargılar da bu çerçevede oluştu. Kökleri son mülteci dalgası dönemine (ikinci Dünya Savaşı yılları) uzanan ve diasporanın iletişimsel alanında yarım asırdan fazladır dolaşımda olan bu kalıp yargılar, geç dönem (20. yy. sonu - 21 yy. başı) geri dönüş karşıtı eğilimlerde katalizatör rolü oynadılar. Demir Perde'nin kalkmasına ve Kafkasya'ya yapılan ilk ziyaretlere, Çerkes aktivistlerin Anavatan imgesini romantize etme çabalarına ve perestroyka sonrası Kafkasya'daki (daha geniş anlamda Rusya'daki) yaşam hakkında idealize düşüncelerin propagandasını yapmak gibi kısa vadeli siyasi amaçlara bağlı olarak yaygınlaştılar. ${ }^{5}$

Olumsuz kalıp yargıların içeriği siyasi, ekonomik ve dini özgürlüklerin olmamasına, Çerkes toplumunun geleneksel değerlerinin aşınmasına ve toplumsal bağlarının çözülmesine ilişkindir. Ancak, belirtmek gerekir ki, buna rağmen tarihi Çerkes vatanının (Heku(j)) "kültürel metropol" statüsü korunmaktadır.

$\mathrm{Bu}$ araştırma çerçevesinde, Kafkasya'dan gelen derlemecinin kaynak kişiler tarafından ne ölçüde kendi topluluğunun, kendi devletülkesinin temsilcisi olarak görüldüğü üzerine yoğunlaştık. Elbette,

\footnotetext{
${ }^{5}$ Bu konuda Çerkes diasporasından şair ve toplum adamı Mevlüt Atalay ile mülakatımıza bakabilirsiniz. Psıne dergisi, № 10, Nalçik, 2012, s. 30-32.
} 
tarihi vatandan gelen halkbilimciler ve antropologlar her şeyden önce değerli konuk statüsündedirler. Fakat bizim pratiğimizde Kafkasya hakkındaki sorulara cevap vermemiz ve kolektif tasavvurlarla bağlantılı iletişimsel bariyerleri aşmamı gereken durumlar oldu.

Derlemecinin ve kaynak kişinin iletişim sürecinde toplumsal davranış tabuları, onların yayılma sınırları ve koşulları örtük biçimde gerçekleşirler. Kinesik-proksemik ${ }^{6}$ tutum, toplumsal davranış becerisini ortaya çıkaran araçlardan biridir. Kaynak kişilerin hiyerarşik oturma düzeni, kadrajda kaçınma geleneğinin uygulanması, derlemeci için bir emare olarak kaynak kişinin duruşu, bütün bunlar "bizden" veya "yabancı" davranışı olarak okunabilir.

Kayıt sırasında toplumsal davranış tabularının konvansiyonel ihlali, örneğin, kameraya ışık vurmaması için "yüksek" yerden "daha aşağı" yere geçme isteği genelde kolayca ve anlayışla kabul edilir. Ancak, alışılmadık biçimde "aşağı" yerde oturan kaynak kişi birinin aniden içeri girmesiyle rahatsızlık hissedebilir.

Derlemecinin ve kaynak kişinin iletişim sürecinde, diaspora koşullarında mutlaka folklor sözünün "seslendirilmesi" sorunu dile getirilir. "Bizzat sözlü metin sadece burada ve şimdi gerçekleşmektedir; onun gerçekliği sadece seslendirilme sürecindedir; seslendirilmediği sürece o, bilinen anlamda mevcut değildir." [Neklyudov].

Kaynak kişinin dilin ve kültürün kaybını eskatolojik duygularla tasvir ettiği durumlarla çok kez karşılaştık. "Sana bugün anlattıklarımı herhalde kırk yıldır kimseye anlatmadım", diaspora alanı için tipik cümledir. Giriftlik ve bağlama yüksek bağımlılık folklor sözünün dramatik kaderini ve onun taşıyıcısının zihinsel-dilsel yalnızlığa mahkumiyetini önceden belirler.

Vyaçeslav V. İvanov, ölen veya ölmekte olan dillerden bahsederken benzer bir örnek veriyor: "Aralık 1991'de Hokkaido'daki huzurevinde bu dilde (Aynu - M.P.) mitolojik metinleri hatırlayan yaşlı bir kadın bulmayı başardım. Bana dedi ki: "Uzaktan geldiğini biliyorum, ama yine gel. Burada konuşacak kimse yok, etrafta sadece Japonlar var." [ivanov].

6 Kinesik-proksemik: Jestler, duruş ve mimikler aracılığıyla aktarılan; iletişimde bulunan kişiler arasındaki fiziki mesafe. 
Çerkes diasporasında "geleneksel Çerkes" (metalogik) iletişim tarzının muhafaza edildiğini gözlüyoruz. Bu, antropoloğun çalışması gereken kentli topluluklar için de karakteristiktir. Derlemeci için yararlı olabilecek ya da aksine risk oluşturabilecek durumlar çoğunlukla onun kaynak kişilerle iletişiminde oluşturduğu toplumsal davranış alışkanlıklarına ve etik kaynaklarına bağlıdır. Profesyonel yetkinlik ve yerel geleneğe "nüfuz" için yeterli süre, elbette, başarılı bir alan çalışmasının önemli bileşenleridir. Fakat bunların yanında, "Adığe habze" ve "Adığağa" (geleneksel Çerkes davranış ve moraletik normları) kurallarına uyulması, Kafkasya'dan gelen derlemeci için onun "bizden" olarak kabul edilmesinde gerekli koşuldur.

Her somut olayda sayılan etkenler kendi bileşimini oluşturur, kendi nüanslarına sahiptir. Temasın özelliğine önemli etki eden durumlardan biri diasporanın koşullarıdır. Burada kaynak kişi tarafından kendini onaylatma ihtiyacı, onun tarihi vatanın temsilcisine yönelik tam bilinçli olmayan merakı, kendi yeterliliğini gösterme yönündeki bilinçaltı isteği, derlemeciyi tam da burada, onun bölgesinde geleneğin herhangi bir yerden daha iyi ve "daha doğru" korunduğuna ikna etme çabası görülür. Aynı zamanda anlatıcı "sadece kendi adına değil, temsilcisi olduğunun bilincinde olduğu yerel topluluk için de" sorumluluk hisseder [Fadeyeva: 18]. Konuşulan taraf hakkında yeterli bilginin olmaması, derleyicinin ve kaynak kişinin toplumsal davranış normlarına farklı yaklaşımı (biri bunları geçmişte kalmış gereksiz kurallar olarak görürken, diğerinin bunun habze olduğunu ve uyulması gerektiğini düşünmesi) bazı durumlarda derlemecinin ve kaynak kişinin iletişimini zorlaştırabilir. Her jest veya söz geniş kapsamlı simgesel içerikle doldurulabilir ve kendince "okunabilir"; beklenmedik şekilde şiddetli pozitif veya negatif tepki yaratabilir. Antropoloğun bunları göz önünde bulundurması gereklidir.

Görüldüğü gibi, diaspora alanında derlemecinin ve kaynak kişinin iletişiminin karakteri kültürel ve tarihsel bazı hususlarla belirlenir. Bunların bir kısmı, kuşkusuz, tüm Çerkes folklor alanını için geçerlidir. Dolayısıyla, tarafımızdan yapılan gözlemler ve çıkarılan sonuçlar, coğrafi (yerel-kültürel ve alt etnik) aidiyetlerden bağımsız olarak alan pratikleri için yararlı olabilir. 


\section{KAYNAKÇA}

Fadeyeva L. V. (2008), "Rasskazçik i kommentator: pozitsii v ustnom povestvovanii, Aktualnıye problemı polevoy folkloristiki", Sbornik nauçnıh trudov. Vıp. 4 - Sıktıvkar: İzd-vo SıktGU, 15-23.

İvanov Vyaç. Vs. (2015), “Lingvistika tretego tısyaçeletiya: Voprosı k buduşçemu", http://www.philology.ru/linguistics1/ivanov-04a.htm

Klyaus V. L. (2006), "K probleme videofiksatsii folklora, Perviy Vserossiyskiy kongress folkloristov", Sbornik dokladov, T. III, Moskva, 83-97, 95.

Neklyudov S. Y. (2015), Zvuçaşeye slovo $v$ folklore. http://www.ruthenia. ru/folklore/neckludov13.htm .

Paştova M. (2014), "Bir Uzunyayla "Öyküsü" Diaspora Hakkında Bir Halkbilim Araştırması", Geçmişten Geleceğe Çerkesler Kültür, Kimlik ve Siyaset", ed. Sevda Alankuş ve Esra Oktay Arı, Ankara, 285-291.

Paştova M. M. (2012), "Folklor v çerkesskoy diaspore Turtsii: funktsionalnıye i regionalno-lokalnıye osobennosti", Folkloristika i kulturnaya antropologiya segodnya. Tezisı i materialı mejdunarodnoy şkolıkonferentsii, Moskova, RGGU, 418-425.

http://www.ruthenia.ru/folklore/may2012proceedings.pdf

Unarokova R. B. (2004), "Folklor adıgov Turtsii. Vstupitelnaya statya", Tırkuyem yis adığeher. Orıuateher (Тыркуем ис адыгэхэр. Іорыlуатэр) (Çerkesçe). , ed. R.B. Unarokova, Maykop, 15-24. 